\title{
Taste and appetite regulation in the elderly
}

\author{
Marion M. Hetherington \\ Department of Psychology, University of Dundee, Dundee DD1 4HN, UK
}

'We ought not to heap reproaches on old age, seeing that we all hope to reach it.'

Bion 2 BC

'Senescence begins, and middle age ends,

The day your descendants, outnumber your friends'

Ogden Nash 1964

The Belgian mathematician Quetelet (1835) in his treatise on human development wrote 'Man is born, grows up and dies according to laws which have never been properly investigated either as a whole or in the mode of their mutual reactions', thereby reinforcing our awareness that ageing is an inevitable and natural process in life but that this process is not well-understood. Quetelet (1835) made observations on the laws of development and aging by examining crosssectional data sets, a methodology which is employed frequently in modern times. Over the last 150 years considerable insight into developmental processes across the lifespan has been afforded by both cross-sectional and longitudinal studies. Large national surveys such as the Baltimore Longitudinal Study of Aging (US Department of Health and Human Services, 1984) demonstrate profound changes in lifestyle, health, nutrition and economics of the population as a function of ageing, and permit a window on this, our most certain and natural fate.

\section{Specific issues associated with ageing Definitions}

The age of retirement was often used as the defining age of the elderly, and certainly early studies of the aging population clustered all older adults aged 64 years and over into the same group. Recently retired adults are likely to be more prosperous, active and healthy than elders in their $80 \mathrm{~s}$. Thus, in order to examine physical, psychological and economic changes with aging, there is general agreement, that people aged 65-74 years are considered the 'young-old', those aged $75-84$ years as the 'old-old' and those aged 85 years and over as the 'oldest old'. These categories are meaningful in appreciating differences within the elderly population. For example, only $6 \%$ of young-old report difficulty in at least one activity of daily living, compared with $34 \%$ of those aged 80-85 years (Leon \& Lair, 1990). Unfortunately, such categories have not been widely used in the published literature.

Definitions of ageing include any structural and functional changes which occurs across the lifespan. The sequence of age-related changes is predictable within a species, but the rate at which these changes occur differs between individuals (Schlenker, 1993). Studies of ageing focus on the physiological and behavioural features of the ageing process as well as the underlying biological, socio-cultural, economic and psychological factors which influence this process. Since chronic illness is extremely common in older adults, and comparatively uncommon in younger adults, it is not surprising that there has been a stronger emphasis on the study of age-related vulnerability to disease (geriatrics) than on normal aging (gerontology). Despite four in every five adults aged 65 years and over having at least one chronic illness, the majority of non-institutionalized elderly describe their health as excellent, very good or good (US Government, 1990). This finding may indicate the willingness of the elderly population to expect illness as a normal aspect of ageing.

\section{Homeostatic control}

The ageing process is highly complex, influenced by a multitude of physical, psychological, economic, social, cultural and environmental factors. Perhaps the single most defining characteristic of physiological ageing is a decline in the ability to respond to changes in either the internal or external environment (Schlenker, 1993) to achieve optimal homeostatic functioning. This fundamental change in responsiveness provides a possible explanation for the general decline in physical and psychological systems as a function of ageing.

The rate of recovery to homeostasis is delayed with ageing. Physiological responses of the major organ systems such as the heart, lungs, kidneys and nervous system decrease compared with levels observed at age 30 years (US Department of Health and Human Services, 1984). This age-related loss of responsiveness is dependent on the number and coordination of organ systems involved. By age 80 years neuronal conduction velocity decreases by $15 \%$, whereas resting cardiac output, which requires coordination at both neural and muscular levels, declines by $30 \%$.

In considering age-related changes in any physiological system such as taste function or appetite regulation, it is important to recognize that both are likely to diminish over time and to be affected by chronic illness. Given individual variations in the physiological rate of ageing, efforts can be made to offset natural ageing processes in an attempt to improve taste perception and the expression of appetite in the elderly. The following review will examine the potential contribution of both changes in taste function and appetite 
regulation in mediating changes in energy intake by the elderly, and will outline any implications of this research in caring for the elderly.

\section{Body mass}

The rationale for examining taste perception and appetite regulation in the elderly, quite apart from obvious contributions to our conceptualization of the laws of development, is to examine the potential link between changes in taste, appetite, energy intake and body mass as a function of ageing. Thus, much of the work on taste and appetite is conducted with a view to understanding how changes in these systems influence the food intake side of the energy balance equation. Ultimately these research endeavours assist in answering questions about changes in body weight and their relation to morbidity and mortality in the elderly.

Whereas excess body weight is identified as a considerable health problem in the general population, loss of body mass is the greater problem for the ageing population (Andres, 1995). Determining the association between body weight, ill-health and mortality in elderly individuals is both complex and controversial. Put simply, the greater the difference between current body weight and ideal weight-forheight, the greater the risk of mortality. For example, in obese men aged $20-45$ years there is a particularly high risk of hypertension, hyperlipidaemia and diabetes. As the population ages, however, risks of developing such illnesses increase for both obese and non-obese men and women. Furthermore, underweight status in people aged 60 years and over decreases life expectancy (Schlenker, 1993), whereas according to Andres (1985) mild or moderate overweight in the elderly is not a potent risk factor. There seems to be a U-shaped relationship between BMI and total mortality in the elderly. Indeed, Andres (1989) has argued that the optimal weight for survival for 65 year olds is higher than the optimal weight for 25 year olds. The implication of Andres' (1989) argument is that weight gain over time is associated with lower mortality in the aged. The Gerontology Research Center (Andres, 1985) has devised age-specific tables of ideal weight ranges, which have been adjusted for a weight increase of $4.5 \mathrm{~kg}(10 \mathrm{lb})$ per decade of life.

Willett (1997) questions this rationale, since low bodyweight status in the elderly combines populations of individuals who have always been active and lean and those who are losing weight as a function of illness. Significant weight loss in the elderly is likely to be due to various diseases which increase chances of mortality, as well as the effects of ageing. Rumpel et al. (1993) suggest that the increased risk of death is limited to those who have lost weight, not to those who have always been lean. Nevertheless, it would appear from longitudinal studies that there is a general decline in body fat and lean mass with a resultant decrease in body weight from age 50 years (Morley, 1997). Thus, a reduced BMI caused either by illness and/or ageing increases risk of mortality.

From the age of 50 years, it is estimated that $3 \mathrm{~kg}$ lean body mass per decade is lost (Dwyer, 1993). This could reflect the tendency towards a more sedentary lifestyle, reduced food intake, a decrease in resting energy metabolism, the onset of illness, appetite-suppressant medication, or a combination of these. The aetiology of declining body mass in the elderly is likely to be multifactorial. A key issue in this equation is the consistent observation across different nations of reduced energy intake over the lifespan.

\section{Declining energy intake}

Longitudinal studies conducted in the USA (Hallfrisch et al. 1990; Koehler, 1994) and in Sweden (Sjogren et al. 1994) have demonstrated a reduction in energy intake with increasing age. Cross-sectional data from the National Health and Nutrition Examination Survey (1994) confirmed this observation, showing a fall in food consumption between age 20 and 80 years. According to Morley (1997) this decline in intake was achieved in part by eating less overall, but specifically by consuming a greater percentage of energy as carbohydrate and consuming significantly less absolute amounts of fat.

In support of this proposition de Castro (1993) investigated $7 \mathrm{~d}$ diet records in 307 healthy adults aged $20-80$ years and found that the elderly consumed a lower proportion of total intake as fat. Additionally, total daily energy intake declined with age for both men and women. Lower energy intakes were associated with consumption of smaller meals eaten at a slower rate in older adults compared with younger adults. Ageing reduces overall energy intake and changes the pattern and rate of food intake.

Wurtman et al. (1988) offered identical diets to elderly and young subjects who were residing in a clinical research facility over a period of $4 \mathrm{~d}$. They found that elderly subjects consumed fewer snacks than young subjects. Again this observation indicates that pattern of eating is influenced by age as well as total energy intake. Also, Wurtman et al. (1988) found that older adults consumed less energy, fat and carbohydrate than young adults. Morley (1997) has suggested that re-analysis of this data indicates that the reduced energy intake in the elderly was due to a reduction in fat rather than carbohydrate.

Reduced fat intake in the elderly has been reported in large, national food surveys; for example, the National Center for Health Statistics (1987) in the USA demonstrated lower fat intake between 1960 and 1980, particularly in women aged 65-74 years of age. In part, this has been attributed to a greater awareness of healthy eating guidelines and a willingness to change diet to improve health (Popkin et al. 1992).

Moreover, it can be argued that changes in the pattern of eating (consuming fewer snacks, smaller meals and eating more slowly), and reductions in fat and total energy intake, reflect changes in the regulatory systems controlling appetite and energy intake.

\section{Appetite regulation \\ Thirst and fluid intake}

Evidence of changes in appetite with ageing has been accumulated in a variety of ways. Subjective ratings of hunger, appetite and fullness have been monitored before and after meals in laboratory and free-living contexts. Responses to energy deprivation, to ingestion of preloads of differing energy and nutrient contents, to nutrient infusions and to 
estimated or actual gastric contents have been measured to provide insight into appetite regulation in the elderly. Since the primary feature of the ageing process appears to be the loss of responsivity to internal and external cues in determining physiological status, evidence of dysregulation in the experience of thirst and control of fluid intake provides an informative and important model for understanding appetite and the control of energy intake.

The elderly often fail to report feeling thirsty in the face of frank dehydration. Phillips et al. (1984) produced significant dehydration in healthy young and elderly males using $24 \mathrm{~h}$ water deprivation and consumption of a dry diet. The elderly demonstrated more dramatic physiological changes in osmolality and $\mathrm{Na}$ concentration, but during ad libitum access to tap water elderly subjects failed to rehydrate to predeprivation levels, whereas young males did so successfully. Despite clear physiological evidence of dehydration, the elderly did not respond to these signals appropriately. Further evidence of this failure to experience thirst comes from Crowe et al. (1987), who found that following a water load and no access to fluids for $7 \mathrm{~h}$ young subjects demonstrated increasing levels of thirst on subjective ratings, whereas the elderly reported no change in thirst ratings despite physiological indices of an osmotic thirst stimulus.

\section{Evidence of appetite dysregulation}

Roberts et al. (1994) found that following a period of food deprivation, intake of food to compensate for deprivation was significantly less in elderly subjects compared with younger subjects. Rolls et al. (1995) compared short-term energy regulation in healthy elderly and young subjects. Baseline intake of energy was significantly smaller in elderly men relative to young men. However, following fixed preloads of yogurt, elderly males failed to regulate subsequent intake appropriately compared with young males. Overall, elderly men overate in response to the preloads by between 10 and $30 \%$ relative to baseline intake. In another study comparing ad libitum consumption of lunch (consisting of sandwiches and juice) following preloads of water, low- or high-calorie jelly, we found that elderly women failed to adjust intake according to the energy content of the preloads, with greatest intake occurring during the highenergy condition (Longbottom \& Hetherington, 1995). In response to underfeeding (deprivation) and to energy loads, elderly subjects are therefore less accurate and less sensitive to such challenges than young adults.

Subjective ratings of hunger in elderly subjects were only weakly correlated with the amount eaten in a meal, according to de Castro (1993) who used free-living elderly adults. Also, correlations between estimated stomach contents and ratings of hunger were significantly weaker for elderly subjects than for young subjects. Further confirmation of these findings taken from $7 \mathrm{~d}$ diet records has been documented in laboratory studies. Clarkston et al. (1997) examined appetite ratings, gastric emptying and total gut transit following an overnight fast and after a test meal ingested at 08.00 hours. Elderly subjects reported significantly less desire to eat and less hunger than young subjects following the meal. Gastric emptying of solids and liquids was slower in elderly subjects.
Taken together, de Castro's (1993) findings suggest that elderly people are less responsive than young adults to stomach contents, and Clarkston et al. (1997) have demonstrated both that elders failed to show normative levels of appetite and hunger in response to a meal, and that delayed gastric emptying might weaken the association between inter-meal interval and the experience of hunger and appetite.

Delayed gastric emptying, and lower hunger and appetite in response to meal intake, with the resultant overall decrease in food intake in elderly subjects, may be attributable to changes in the secretion of gut hormones such as cholecystokinin. Isoenergetic nutrient infusions directly into the duodenum of glucose or lipid did not produce the same degree of suppression of hunger and desire to eat in elderly subjects compared with young subjects (Cook et al. 1997). This demonstrates that elders are less responsive to the presence of nutrients in the small intestine, and that its effects on hunger and appetite are attenuated. However, the mechanism for this is unclear, and in studies of circulating levels of cholecystokinin, elevated levels are found only in elders with frank anorexia (for a review, see Morley, 1997). There is now mounting evidence of reduced responsivity to fasting, energetic preloads and nutrient infusions, and of the development of early satiety coupled with delayed gastric emptying with age, but the underlying mechanism for each of these remains to be elucidated.

\section{Sensory-specific satiety and food cravings}

Hedonic responses to foods, changes in these responses as a function of eating, and the expression of food cravings have been investigated in the elderly. In general, consumers select foods they like and avoid foods they dislike. Until recently, the effects of ageing on liking and cravings for foods were unexplored, yet pleasantness and desire for foods are powerful determinants of food choice (Hetherington \& Rolls, 1996). Rolls \& McDermott (1991) investigated changes in the pleasantness of the taste of a food as it is eaten, or sensory-specific satiety, across four age-groups (adolescents, young adults, older adults and elderly). They reported that sensory-specific satiety failed to develop in elderly adults compared with the three other age-groups of subjects. The implication of this finding is that lack of sensory-specific satiety will be accompanied by a failure to respond to the enhancing effects of variety in the diet. Certainly, some studies indicate that elderly adults tend to consume a more monotonous diet (Fanelli \& Stevenhagen, 1985), and that the elderly do not respond to the stimulatory effects of variety on fluid intake (Phillips et al. 1991). In contrast, a more recent study investigating dietary variety in young and old healthy adults found that older adults consumed a more varied diet as a method of offsetting sensory loss (Drewnowski et al. 1997).

Changes in sensory-specific satiety might be explained by the general decline in sensory acuity associated with ageing rather than changes in appetite regulation. This possibility has been rejected by Rolls and her colleagues (Rolls \& McDermott, 1991; Rolls, 1992; Rolls et al. 1995), since loss of olfactory function did not correlate with sensory specific changes in taste or smell, and elderly subjects reported similar hedonic ratings of the test foods to younger groups. 
Pelchat (1997) investigated food cravings in young and elderly adults, since it may be argued that cravings arise as a function of more monotonous diets, lower energy intakes or nutrient deficiencies. Alternatively, cravings might be mediated by the same regulatory mechanisms as those controlling appetite, energy intake, energy compensation and sensoryspecific satiety. Pelchat (1997) found support for this latter proposal, since elderly subjects reported fewer food cravings than young adults and a smaller number of different foods which are craved. This study provides evidence of a general decline in appetite regulation with ageing.

In summary, alterations in appetite regulation with ageing influence the amount of food consumed, pattern of eating, and ability to regulate appropriately, to experience normative changes in hunger and appetite, and to demonstrate sensoryspecific satiety.

\section{Evidence of hyperphagia}

In common with most studies of appetite in the elderly, the present review has focused on loss of appetite with age. Two recent studies by Keene \& Hope $(1997 a, b)$ in Oxford indicate that excess appetite and overeating in a particular section of the elderly population is worthy of scientific scrutiny and clinical consideration.

Senile dementia occurs in about $6 \%$ of the ageing population (Kay \& Bergman, 1980) and is associated with weight loss (Berlinger \& Potter, 1991). Weight loss in dementing adults is attributable to a variety of problems including: cognitive impairment disrupting normal cooking, preparation and consumption of food items; sensory impairment; depression; increased energy requirements (e.g. due to pacing); co-morbidity; social factors. In contrast to these general observations, a study comparing the dietary intake of hospitalized demented patients, community-based demented patients and age-matched controls, found that both groups with dementia consumed significantly more energy, protein, vitamins and minerals than the controls (Burns et al. 1989). In this study, there were no correlations between degree of cognitive impairment and various indices of nutritional status. According to Keene \& Hope $(1997 a, b)$ about onethird of dementia sufferers actually increase their food intake relative to premorbid levels of intake. These authors also report that about $15 \%$ of a sample of eighty-five dementing patients consumed non-food items (e.g. pet food or potato peelings). To understand changes in eating behaviour as a function of dementia, hyperphagia and ageing, two experiments were conducted.

In one experiment, hyperphagic dementia sufferers were compared with non-hyperphagic controls and normal elderly subjects using both a single food meal or a mixed meal. Under both conditions, hyperphagic patients consumed significantly more than either control group (Keene \& Hope, 1997a). In a second experiment food choice and macronutrient intake were investigated in four groups of subjects (hyperphagic demented, non-hyperphagic demented, nondemented elderly and young controls). The proportion of protein consumed by the elderly was significantly less than that consumed by young subjects. The proportion of protein consumed was lowest in the hyperphagic dementia group, and sweet foods were consumed in the greatest quantities by this group. Excess intake observed in dementia is not simply an attempt to consume more of all foods, but is selective for sweet foods to the detriment of foods high in protein. The authors propose that a possible mechanism underlying selective intake of sweets is due to reduced brain serotonin in Alzheimer's disease. Hyperphagic demented patients may seek out sweet foods as a method of increasing the availability of serotonin (Keene \& Hope, 1997b).

An alternative explanation for increased intake in dementia, but one which has not been addressed empirically, is that hyperphagia may be related to gross memory loss, a failure to recognize culturally appropriate foodstuffs (e.g. in pica, the condition in which individuals consume non-edible substances) or culturally acceptable amounts. Rozin (1996) described a study in which amnesic patients were offered a culturally appropriate lunch, then this was cleared away and a second and third full lunch were offered in turn. Amnesic patients with severe loss of short-term memory failed to terminate eating appropriately and continued to consume each lunch as it was laid down to them. Excess eating or inappropriate consumption may be associated with disruption of memory for previous intake and typical or appropriate amounts of food.

Whatever the underlying cause of hyperphagia in dementia, it is clear that ageing and the attendant changes in cognitive function have an impact on overall energy intake and food choice. Cognitive impairments occurring in dementia, or loss of memory with ageing, may exacerbate other changes in function such as loss of appetite and declining sensory function. In combination, these aspects of the ageing process are likely to contribute to extreme conditions such as hyperphagia or anorexia, and to the less dramatic changes in eating and appetite observed in normal ageing.

\section{Taste function}

Taste perception

Loss of sensory acuity with ageing may lead to a decline in the pleasantness of the taste and smell of foods. Sensory loss which influences the appeal of foods may reduce the amount of food consumed. Flavour is rated as highly important in determining food choice in the elderly (Schiffman \& Gatlin, 1993), and since flavour perception is the outcome of both taste and smell function, changes in the ability to taste and smell have been investigated widely in the elderly.

Stevens et al. (1995) proposed that almost everyone will experience a decrement in taste sensitivity as a function of age. In an experiment comparing fifteen subjects aged 64 years and over with fifteen younger subjects (under 27 years) on sucrose thresholds, elderly subjects demonstrated clear evidence of taste weakness compared with younger subjects. When threshold scores were averaged, young subjects showed a greater uniformity of sensitivity, whereas the older subjects demonstrated large individual differences, reflecting differential rates of physiological ageing. This reinforces the notion that ageing involves not only loss of function, but can occur at variable rates across individuals.

In a review of the literature from 1966 to 1997 , Schiffman (1997) concluded on the basis of a large number of studies that there is strong and reliable evidence of olfactory and 
gustatory decline with age. In addition, illness, certain drugs, surgical interventions and exposure to some environmental hazards have a deleterious impact on taste and smell. Furthermore, loss of smell and taste function may compromise both nutrition and immunity (Schiffman, 1997).

In experimental studies of the effects of flavour enhancement of foods on intake in the elderly, Schiffman \& Warwick (1993) found that a 3-week exposure to a flavour-enhanced diet resulted not only in greater intake of some foods, but improved immune function and grip strength compared with 3 weeks on the unenhanced institutional diet. However, total macronutrient and energy intake did not differ across conditions. Elders preferred the flavour-enhanced versions of food and consumed more of some of the enhanced foods, but this was not sufficient to increase significantly overall energy intake. Sustained exposure to flavour enhancement for longer than 3 weeks may be necessary to promote an increase in total energy intake.

\section{Smell perception}

Olfactory function in healthy elderly women was investigated by Duffy et al. (1995) using both orthonasal (odour threshold and identification) and retronasal (flavour threshold in a sweet gelatin medium) stimuli. Almost half the elderly women tested displayed olfactory loss. Lower olfactory perception was significantly correlated with lower interest in foods (cooking, consuming a variety of foods), reduced preference for sour, bitter and pungent tastes, higher intake of sweet foods and a greater risk profile for cardiovascular disease. These authors concluded that loss of smell function may interfere with the maintenance of a healthy diet (e.g. reduced citrus fruit intake, lower consumption of low-fat milk products and greater intake of sweet foods). The effects of ageing on olfaction may have a detrimental effect on food intake by reducing interest in food and eating, and by decreasing amounts and types of foods selected, prepared and consumed.

Drewnowski (1997) states that although sensory responses to the taste, smell and texture of foods determine food preferences and eating patterns, sensory responses do not predict food consumption on their own. In a study of salt taste perception and preference, Drewnowski et al. (1996) found that elderly subjects preferred a less salty chicken broth than young subjects, and did not differ in accuracy of sensory evaluations of the broth compared with young subjects. These taste perceptions and preferences did not relate to actual $\mathrm{Na}$ intakes recorded using $24 \mathrm{~h}$ dietary recall.

More important than taste responses for food choice, Drewnowski (1997) argues, are attitudinal, sex, age, social and economic factors. Drewnowski (1997) has also demonstrated that taste responsiveness is mediated by eating pathology and body weight (i.e. greater preference for high fat stimuli in obesity). Anorexia, hyperphagia and other eating disorders will have an impact on taste preferences, responsivity and food choice.

\section{Eating disorders}

Considerable efforts have been made to understand changes in appetite and food intake as a function of ageing, particularly given the particular vulnerability of the elderly to reduce energy intake, lose body mass, experience loss of appetite and develop indicators of malnutrition (Burns et al. 1989). Much less attention has been paid to the development of eating disorders in old age. A possible explanation for this observation is that eating disorders are typically associated with young girls and women, not with the elderly. Nevertheless, case studies of bulimia (Hsu \& Zimmer, 1988; Jonas et al. 1984) and anorexia nervosa (Hsu \& Zimmer, 1988; Nagaratnam \& Ghougassian, 1988) in older adults have been published, as well as reports demonstrating abnormal eating attitudes, body-image distortion and body-weight dissatisfaction with ageing (Miller et al. 1991; Hetherington \& Burnett, 1994).

Desire to lose $4.5 \mathrm{~kg}(10 \mathrm{lb})$, on average, was reported by fifty normal-weight, healthy elderly women and about one-third of these women were currently on a diet to lose weight (Hetherington \& Burnett, 1994). This finding mirrors the experience of young normal-weight women. In a largescale European study involving over 16000 students, Bellisle et al. (1995) reported that $44 \%$ of the women in the sample were trying to lose weight despite a low average BMI (20.5). Pliner et al. (1990) reported that females aged between 10 and 79 years are more concerned about eating, body weight and physical appearance, and have lower appearance self-esteem than men. The experience of body dissatisfaction and concern for eating and weight is normative for women of all ages.

A study of dietary changes in elderly American adults indicated that although health advocacy had resulted in reductions in serum cholesterol and fat intake, particularly in those aged 65-74 years (Popkin et al. 1992), insufficient guidance had been given to increase intake of fruits, vegetables and fibre. A more recent study of fruit and vegetable consumption in the elderly found that women consumed significantly more fruit than men, and that single elderly women were much more concerned about body image than single elderly men (Donkin et al. 1998). These authors found that elderly women were three times more likely than elderly men to be on a weight-watching diet (Donkin et al. 1998).

Elderly adults demonstrate awareness of health risks associated with obesity by reducing fat intake (Popkin et al. 1992), by engaging in weight-loss diets (Hetherington \& Burnett, 1994; Donkin et al. 1998), and may even report fear of weight gain (Morley et al. 1989). In contrast, concomitant efforts to increase intake of healthy foods tend to be absent (Popkin et al. 1992). Moreover, in the ageing population, where loss of body weight is associated with greater mortality, energy intake decreases over time, and vulnerability to illness is especially high, efforts to lose weight and concern about body image may be misplaced (Hetherington \& Burnett, 1994).

\section{Conclusions and implications}

Overall, ageing is associated with inevitable changes in body mass, appetite and food intake, ranging from profound anorexia and weight loss, hyperphagia and eating problems, to more subtle changes in appetite, energy intake, choice of foods, pattern of eating and sensory acuity. In addressing Quetelet's (1835) challenge to investigate properly the laws 
of development across the lifespan, accumulated wisdom about the process of ageing suggests that some change is expected for all across the lifespan, particularly the ability to respond appropriately for optimal physiological or psychological function. However, significant individual differences in the rate at which physiological aging occurs is also a characteristic of the ageing process.

Given that the general detrimental effects of ageing cannot be reversed, specific clinical, community and societal interventions which capitalize on individual differences in the rate of physiological ageing may provide opportunities to enhance the quality of life of the aged, through improved public health messages on optimal diet for the elderly, achievement of age- specific weight targets, enhancement of the sensory properties of foods, sensitivity to the loss of appetite in the elderly, and greater awareness of what is reasonable to expect as indicative of normal aging and what is treatable as a secondary aspect of ageing.

\section{References}

Andres R (1985) Mortality and obesity: the rationale for agespecific height-weight tables. In Principles of Geriatric Medicine, pp. 311-318 [R Andres, EL Bierman and WR Hazzard, editors]. New York, NY: McGraw-Hill.

Andres R (1989) Does the 'best' body weight change with age? In Eating, Sleeping and Sex, pp. 99-107 [AJ Stunkard and A Baum, editors]. Hillsdale, NJ: Erlbaum.

Andres R (1995) Body weight and age. In Eating Disorders and Obesity, pp. 65-70 [KD Brownell and CG Fairbum, editors]. New York, NY: Guilford Press.

Bellisle F, Monneuse M-O, Steptoe A \& Wardle J (1995) Weight concerns and eating patterns: A survey of university students in Europe. International Journal of Obesity 19, 723-730.

Berlinger WG \& Potter JF (1991) Low body mass index in demented outpatients. Journal of the American Geriatrics Society 39, 973-978.

Burns A, Marsh A \& Bender DA (1989) Dietary intake and clinical, anthropometric and biochemical indices of malnutrition in eiderly demented patients and non-demented subjects. Psychological Medicine 19, 383-391.

Clarkston WK, Pantano MM, Morley JE, Horowitz M, Littlefield JM \& Burton FR (1997) Evidence for the anorexia of aging: gastrointestinal transit and hunger in healthy elderly vs. young adults. American Journal of Physiology 272, R243-R248.

Cook CG, Andrews JM, Jones KL, Wittert GA, Chapman IM, Morley JE \& Horowitz M (1997) Effects of small intestinal nutrient infusion on appetite and pyloric motility are modified by age. American Journal of Physiology 273, R755-R761.

Crowe MJ, Forsling ML, Rolls PA, Ledingham JGG \& Smith RF (1987) Altered water excretion in healthy elderly men. Age and Ageing 16, 285-293.

de Castro JM (1993) Age-related changes in spontaneous food intake and hunger in humans. Appetite 21, 255-272.

Donkin AJM, Johnson AE, Lilley JM, Morgan K, Neale RJ, Page RM \& Silburn RL (1998) Gender and living alone as determinants of fruit and vegetable consumption among elderly living at home in urban Nottingham. Appetite 30, 39-51.

Drewnowski A (1997) Taste preferences and food intake. Annual Review of Nutrition 17, 237-253.

Drewnowski A, Henderson SA, Driscoll A \& Rolls BJ (1996) Salt taste perceptions and preferences are unrelated to sodium consumption in healthy older adults. Journal of the American Dietetic Association 96, 471-474.
Drewnowski A, Henderson SA, Driscoll A \& Rolls BJ (1997) The dietary variety score - assessing diet quality in healthy young and older adults. Journal of the American Dietetic Association 97, 266-271.

Duffy VB, Backstrand JR \& Ferris AM (1995) Olfactory dysfunction and related nutritional risk in free-living, elderly women. Journal of the American Dietetic Association 95, 879-884.

Dwyer J (1993) Childhood, youth and old age. In Human Nutrition and Dietetics, pp. 394-408 [JS Garrow and WPT James, editors]. Edinburgh: Churchill-Livingstone.

Fanelli MT \& Stevenhagen KJ (1985) Characterizing consumption patterns by food frequency methods: core foods and variety of foods in diets of older Americans. Journal of the American Dietetic Association 85, 1570-1576.

Hallfrisch J, Muller D, Drinkwater D, Tobin J \& Andres R (1990) Continuing diet trends in men: the Baltimore Longitudinal Study of Aging (1961-1987). Journals of Gerontology 45, 186-191.

Hetherington MM \& Burnett L (1994) Ageing and the pursuit of slimness: dietary restraint and weight satisfaction in elderly women. British Journal of Clinical Psychology 33, 391-400.

Hetherington MM \& Rolls BJ (1996) Sensory-specific satiety: theoretical frameworks and central characteristics. In Why We Eat What We Eat: The Psychology of Eating, pp. 267-290 [ED Capaldi, editor]. Washington, DC: American Psychological Association.

Hsu GL \& Zimmer B (1988) Eating disorders in old age. International Journal of Eating Disorders 7, 133-138.

Jonas JM, Pope HG, Hudson JI \& Satlin A (1984) Undiagnosed vomiting in an older woman: unsuspected bulimia. American Journal of Psychiatry 141, 902-903.

Kay DK \& Bergman K (1980) Epidemiology of disorders among the aged in the community. In Handbook of Mental Health and Ageing, pp. 34-56 [JE Birren and RB Sloane, editors]. Englewood Cliffs, NJ: Prentice-Hall.

Keene JM \& Hope T (1997a) Hyperphagia in dementia 1: The use of an objective and reliable method for measuring hyperphagia in people with dementia. Appetite 28, 151-165.

Keene JM \& Hope T (1997b) Hyperphagia in dementia 2: Food choices and their macronutrient contents in hyperphagia, dementia and ageing. Appetite 28, 167-175.

Koehler KM (1994) The New Mexico aging process study. Nutrition Reviews 8, Suppl., S34-S37.

Leon J \& Lair T (1990) Functional Status of the Noninstitutionalized Elderly: Estimates of $A D L$ and IADL Difficulties. DHHS Publication no. (PHS) 90-3462. Rockville, MD: US Department of Health and Human Services.

Longbottom P \& Hetherington M (1995) Regulation of food intake and its relevance for adequacy in elderly women. Home Econo. mist 14, 8-10.

Miller DK, Morley JE, Rubenstein LZ \& Pietruszka FM (1991) Abnormal eating attitudes and body image in older undernourished individuals. Journal of the American Geriatrics Society 39 , $462-466$.

Morley JE (1997) Anorexia of aging: physiologic and psychologic. American Joumal of Clinical Nutrition 66, 760-773.

Morley JE, Silver AJ, Miller DK \& Rubenstein LZ (1989) The anorexia of the elderly. Annals of the New York Academy of Sciences 575, 50-58.

Nagaratnam N \& Ghougassian DF (1988) Anorexia nervosa in a 70 year old man. British Medical Journal 296, 1443-1444.

National Center for Health Statistics (1987) Trends in serum cholesterol levels among US adults aged 20 to 74 years. Journal of the American Medical Association 257, 937-942.

National Health and Nutrition Examination Survey (1994) Daily dietary fat and total food intake. Phase 3. 1988-1991. Morbidity and Mortality Weekly Report 43, 116-125. 
Pelchat ML (1997) Food cravings in young and elderly adults. Appetite 28, 103-113.

Phillips PA, Johnston CI \& Gray L (1991) Thirst and fluid intake in the elderly. In Thirst - Physiological and Psychological Aspects, pp. 403-411 [DJ Ramsay and DA Booth, editors]. Berlin: Springer-Verlag.

Phillips PA, Rolls BJ, Ledingham JGG, Forsling ML, Morton JJ, Crowe MJ \& Woilner L (1984) Reduced thirst after water deprivation in healthy elderly men. New England Journal of Medicine 311, 753-759.

Pliner P, Chaiken S \& Flett GL (1990) Gender differences in concern with body weight and physical appearance across the life span. Personality and Social Psychology Bulletin 16, 263-273.

Popkin BM, Haines PS \& Patterson RE (1992) Dietary changes in older Americans, 1977-1987. American Journal of Clinical Nutrition 55, 823-830.

Quetelet MA (1835) Sur l'Homme, et le Développement de ses Facultés (On Man, and the Development of his Faculties). Paris: Bachelier. (Published in English in 1842 as A Treatise on Man.)

Roberts SB, Fuss P, Heymann MB, Evans WJ, Tsay R, Rasmussen H, Fiatarone M, Cortiella J, Dallal GE \& Young VR (1994) Control of food intake in older men. Journal of the American Medical Association 272, 1601-1606.

Rolls BJ (1992) Aging and appetite. Nutrition Reviews 50, $422-426$.

Rolls BJ, Dimeo KA \& Shide DJ (1995) Age-related impairments in the regulation of food intake. American Journal of Clinical Nutrition 62, 923-931.

Rolls BJ \& McDermott TM (1991) Effects of age on sensoryspecific satiety. American Journal of Clinical Nutrition 54, 988-996.

Rozin P (1996) Sociocultural influences on human food selection. In Why We Eat What We Eat: The Psychology of Eating, pp. 233-263 [ED Capaldi, editor]. Washington, DC: American Psychological Association.
Rumpel C, Harris TB \& Madans J (1993) Modification of the relationship between the Quetelet Index and mortality by weight loss history among older women. Annals of Epidemiology 3, 343-350.

Schiffman SS (1997) Taste and smell losses in normal aging and disease. Journal of the American Medical Association 278, 1357-1362.

Schiffman SS \& Gatlin CA (1993) Clinical physiology of taste and smell. Annual Review of Nutrition 13, 405-436.

Schiffman SS \& Warwick ZS (1993) Effect of flavor-enhancement of foods for the elderly on nutritional status: Food intake, biochemical indices, and anthropometric measures. Physiology and Behavior 63, 395-402.

Schlenker ED (1993) Nutrition In Aging, 2nd ed. St Louis, MO: Mosby.

Sjogren A, Osterberg T \& Steen B (1994) Intake of energy, nutrients and food items in a ten year cohort comparison and in a six year longitudinal perspective: a population study of $70-$ and 76-year old Swedish people. Age and Ageing 23, 108-112.

Stevens JC, Cruz LA, Hoffman JM \& Patterson MQ (1995) Taste sensitivity and aging: high incidence of decline revealed by repeated threshold measures. Chemical Senses 20, 451-459.

US Department of Health and Human Services (1984) Normal Human Aging: the Baltimore Longitudinal Study of Aging. NIH Publication no. 84-2450. Washington, DC: US Government Printing Office.

US Government (1990) Aging America: Trends and Projections. Serial no. 101-J. Washington, DC: US Government Printing Office.

Willett WC (1997) Weight loss in the elderly: cause of effect of poor health? American Journal of Clinical Nutrition 66, 737-738.

Wurtman JJ, Lieberman H, Tsay R, Nader T \& Chew B (1988) Calorie and nutrient intakes of elderly and young subjects measured under identical conditions. Journals of Gerontology 43, B174-B 180. 